Revista de Literatura, História e Memória

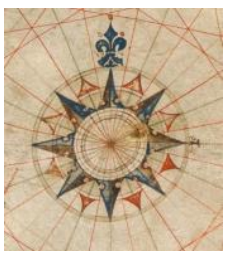

Dossiê: Manifestações de re-existência: a literatura em tempos de repressão

ISSN 1983-1498

VOL. 16 - $\mathbf{N}^{\circ} 27$ - 2020

U N I O E S T E / CA S C A V E L - p. 226-243

\title{
ESCREVIVÊNCIAS DA PÓS-COLONIALIDADE: MEMÓRIA E VIOLÊNCIA NOS BECOS DA MEMÓRIA, DE CONCEIÇÃO EVARISTO
}

Escrevivências of postcoloniality: memory and violence in Becos da memória, by Conceição Evaristo

\author{
Tarik Mateus Adão da Costa de Almeida ${ }^{1}$ \\ Gabriela Soares Nogueira Andreatti ${ }^{2}$
}

RESUMO: O presente artigo propõe-se a realizar uma leitura da obra Becos da Memória, de Conceição Evaristo, tendo como principal referência o conceito de escrevivência, desenvolvido por esta escritora. Propomo-nos a debater a forma como Maria-Nova resgata o próprio passado como um ato de resistência contra a opressão e o silenciamento impostos pelas classes dominantes na pós-colonialidade. A escrevivência tornou-se um conceito chave para a compreensão das narrativas contemporâneas desenvolvidas por escritoras negras, porque estabelece um parâmetro que, não só representa os marginalizados da sociedade brasileira, dando-lhes voz, mas corrobora para a denúncia de um sistema que oprime e silencia o povo negro do Brasil. Dessa forma, pretendemos evidenciar como essas manifestações perpassam esse romance, desembocando em processos de descolonização. Nesse sentido, convoca-se autores como Thomas Bonicci (1998) e Homi Bhabha (1983) em suas discussões sobre pós-colonialismo e sobre o sujeito colonizado, além de autores como Frantz Fanon (1990) e Michael Pollak (1989), que serão de grande importância para a constituição de nossa análise. PALAVRAS-CHAVE: Escrevivência; Memória; Violência; Estudos Pós-Coloniais.

ABSTRACT: This article proposes to analyse the novel Becos da Memória, written by Conceição Evaristo, having as its main reference the concept of escrevivência, developed by this writer. Our objective is to discuss a way in which Maria-Nova rescues her own past as an act of resistance against oppression and silencing imposed by the dominant classes in post-coloniality. Escrevivência has become a key concept for the understanding of contemporary narratives used by black writers, because it established a parameter that, not only represents the marginalized of Brazilian society, giving them a voice, but corroborating for a declaration of a system that oppresses and silences black people of Brazil. In this way, we intend to demonstrate how these manifestations go by this novel, resulting in processes of decolonization. In this sense, authors such as Thomas Bonicci (1998) and Homi Bhabha (1983) are quoted by their discussions about post-colonialism and the colonized subject, in addition to authors like Frantz Fanon (1990) and Michael Pollak (1989), which will be of great importance for the constitution of our analysis.

KEYWORDS: Escrivivência; Memory; Violence; Post-Colonial Studies.

\section{INTRODUÇÃO}

A obra Becos da Memória (2017), de Conceição Evaristo, escrita nos anos de 1980, no

\footnotetext{
${ }^{1}$ Mestrando em Estudos Literários pelo Programa de Pós-Graduação em Letras Universidade Estadual de Maringá.

2 Mestranda em Estudos Literários pelo Programa de Pós-Graduação em Letras Universidade Estadual de Maringá.
} 
Brasil, fora publicada apenas na década de 2000, mais precisamente no ano de 2006. O espaço em aberto marcado pelo tempo, entre a finalização da obra (1986) e a data de publicação, vinte anos depois, reflete a dificuldade que a escritora enfrentou para adentrar ao circuito literário. Nos agradecimentos da $3^{\mathrm{a}}$ edição, realizada em 2017, a autora relembra os vinte anos de espera em que manteve a obra engavetada e, de quando, enfim, pôde festejar a primeira publicação de seu livro, em 2006.

Conceição Evaristo faz parte de um grupo de autores negros que, no Brasil, começaram a publicar seus textos literários nos Cadernos Negros, desde o final da década de 1970 e início da de 1980. Por isso, quando pensamos em literatura de autoria negra feminina, na contemporaneidade, faz-se necessário compreender as dificuldades que essas autoras enfrentam para ingressar no circuito comercial-editorial, ou seja, nas grandes editoras que, muitas vezes, não demonstram interesse na publicação de suas obras. Tais dificuldades, com certeza, estão relacionadas a alguns fatores, dentre eles: o racismo estrutural presente no Brasil e, também, o fato de que, mesmo hoje, a maioria das obras literárias publicadas e reconhecidas, nacional e internacionalmente, são escritas por homens brancos, heterossexuais e de classe média. No entanto, isso não diminui a participação de escritoras negras no ramo literário, que estão, cada vez mais, organizando eventos culturais com o intuito de difundir as artes poéticas contra hegemônicas.

Becos da memória é construído como uma colcha de retalhos, tecida pelas lembranças de Maria-Nova, que reúne as histórias que vivenciou e ouviu em sua infância na favela e as organiza em uma narrativa que apresenta a vida e as dores daqueles que com ela conviviam. Essas histórias fazem parte de uma realidade social oriunda do contexto das favelas. Nesse sentido, podemos dizer que a organização da obra remete, diretamente, ao título da narrativa, pois em cada beco da favela, há uma história, uma memória. Essa união de histórias fragmentadas traz um aspecto de superpovoamento à narrativa, assim como nas favelas. Dessa maneira, Simone Pereira Schmidt afirma que:

Para a construção de seu romance, a autora tomará como mote a estrutura sinuosa e múltipla dos becos da favela, que, percorridos pela narradora, mostram-se, a um só tempo, iguais e diversos, múltiplos, tortuosos, promissores, cheios de histórias de vida (SCHMIDT, 2017, p. 186-187).

Por isso, há a necessidade de compreender o conceito de escrevivência, desenvolvido por Evaristo (2007), já que a autora justifica a importância de narrativas produzidas por escritoras negras no Brasil. Nessa perspectiva, veremos que a multiplicidade de vozes, a 
memória, a opressão e o silêncio são elementos presentes nessas manifestações literárias, principalmente, pela relação intrínseca entre memória e escrevivência, já que uma se dá em benefício da outra. Ou seja, é pela memória que se recupera a experiência histórica, enquanto mulheres negras e periféricas, de forma a manifestar em suas obras as experiências oriundas desse sistema ou dessa "situação colonial"3: "Hoje a recordação daquele mundo me traz lágrimas aos olhos. Como éramos pobres! Miseráveis talvez! Como a vida acontecia simples e como tudo era e é complicado" (EVARISTO, 2017, p. 19).

O presente artigo irá investigar a forma como a narrativa de Becos da memória se constrói como um ato de resistência à violência sofrida pelos habitantes da favela, figurando como resposta ao silenciamento imposto às vozes dessas personagens. Além disso, buscaremos demonstrar como o conceito de escrevivência relaciona-se com a violência nesta obra, elucidando que, em Becos da Memória, a subjetividade das personagens femininas é marcada por violências oriundas de um sistema social, que oprime duplamente a mulher negra.

A escrita, portanto, é aqui enxergada como o elemento que permite a exposição dessas narrativas que, por sua vez, problematizam estruturas sociais que ainda estão presentes em nosso cotidiano. Por este motivo, ela vem com o intuito de libertar e reescrever novas maneiras de enxergar essas existências, tornando-se um ato de descolonização ${ }^{4}$.

\section{ESCREVIVÊNCIA E LITERATURA AFRO-BRASILEIRA}

Estudos contemporâneos de literatura e cultura revelam, hoje, uma maior preocupação no que tange algumas questões de representação de grupos sociais que foram marginalizados

\footnotetext{
${ }^{3}$ Neste artigo, compreendemos por "situação colonial" a definição defendida por George Balandier (2007), o qual compreende o termo como um complexo que está presente nos países colonizados do globo. Para ele, o estudo atual da organização social dessas sociedades que, de alguma forma, busca compreender o momento presente, deve ser feito com referência à essa situação, a qual designa uma relação intrincada entre "sociedade colonizadora" e "sociedade colonizada" e que trouxe diversos problemas, dentre alguns bastante específicos, aos povos subjugados, isto é, colonizados. Dentre os problemas citados pelo sociólogo, encontra-se a continuidade da colonização por instâncias que se enraízam na organização social dessas sociedades.

${ }^{4}$ Compreendemos por ato de descolonização as formas de resistência que se manifestam na literatura produzida por imigrantes ou por grupos étnicos e sociais não hegemônicos e, portanto, periféricos. Os quais, a partir de processos de apropriações linguísticas e das formas literárias do colonizador, passam a criar imagens utópicas em suas produções. Essas imagens e produções podem ser compreendidas como uma resposta às representações ocidentalizadas que, de alguma forma, acabavam por estereotipar essas modalizações. O crítico literário indiano Armando Gnisci (1999) apresenta o conceito de "Literatura dos Mundos", caracterizada pela resistência e pela construção de um discurso que representa um diálogo entre os mundos, ou seja, que traz à tona a diversidade cultural, étnica e, portanto, híbrida dos discursos literários, produzidos por esses grupos. Para ele, o termo descolonização, na literatura, perpassa pelas desconstruções ideológicas propagadas pelo centro hegemônico, a partir do processo de tradução do ex-colonizado, que contesta estereótipos, subalternização e imaginários fantasiosos e folclóricos.
} 
ao longo da história. Dessa forma, a literatura, em um contexto geral, disseminou algumas representações que foram pautadas em construções ideológicas hegemônicas e, por isso, pouco representativas. Nessa perspectiva, podemos verificar importantes pesquisas que abordam e criticam a representação problemática que a personagem negra teve ao longo das décadas trazendo à tona a necessidade de questionar e rever essas representações 5 .

Eduardo de Assis Duarte (2010), em seu artigo, Por um conceito de literatura afrobrasileira, propõe um resgate histórico sobre a produção literária negra no Brasil. $\mathrm{O}$ autor pontua algumas das principais produções e concepções artísticas que colocam a temática negra no centro do protagonismo, evocando denúncias contra o racismo. Além disso, o autor busca evidenciar o que seria o conceito de literatura negra, levantando discussões de obras como a série Cadernos Negros, que trouxe uma enorme contribuição para a formação da literatura negra, no Brasil. Segundo ele, nessa literatura "[...] sobressai o tema do negro, enquanto individualidade e coletividade, inserção social e memória cultural" (DUARTE, 2010, p. 115 ).

A série Cadernos Negros, fundada em 1978, no Brasil, tem como objetivo atuar como um espaço no qual escritores negros e negras possam expor e publicar coletivamente as suas obras. Esta série é publicada anualmente, alternando suas edições entre poemas e contos, sob a responsabilidade do grupo Quilombhoje. Além disso, ela detém uma grande importância, pois formalizou o protagonismo negro no âmbito das artes literárias, sendo resultado de uma série de debates e movimentos históricos empenhados desde a fundação do Teatro Experimental do Negro (TEN) em 1944, por Abdias do Nascimento, e da luta do movimento negro, em geral, que na década de 1970 articulou-se coletivamente para pensar e promover as produções artísticas de matriz africana, "Foi neste clima que os militantes e escritores Cuti e Hugo Ferreira propuseram os Cadernos Negros" (ANTONIO, 2005, p. 15).

Dessa maneira, esta série propõe uma formalização literária do papel negro na literatura brasileira. Podemos dizer que esse processo de formalização histórica, na literatura, apresenta um novo conteúdo sobre a identidade, a ancestralidade e a cultura negra, no Brasil, apresentando poetas e escritores, negros e negras que falam sobre si, isto é, sobre suas subjetividades, perpassando questões como a religiosidade, a africanidade e o racismo, no Brasil. Em suma, sobre o significado do que é ser negro, em nosso país. É nesse panorama, que surge a necessidade da crítica literária repensar termos como literatura negra e afrobrasileira.

\footnotetext{
${ }^{5}$ Ver estudos de Eduardo Assis Duarte (2010), Conceição Evaristo (2009), David Brookshaw (1983), Domício Proença Filho (2004), entre outros.
} 
Ironildes Rodrigues em depoimento a Luiza Lobo verifica que:

A literatura negra é aquela desenvolvida por autor negro que escreve sobre sua raça dentro do significado do que é ser negro, da cor negra, de forma assumida, discutindo os problemas que a concernem: religião, sociedade, racismo. Ele tem que se assumir como negro (LOBO, 2007, p. 266).

Nesse ínterim, o texto literário afro-brasileiro propõe variadas rupturas em relação às representações hegemônicas na história da literatura brasileira. Essas rupturas podem ser aqui pensadas, por duas concepções ou estratégias literárias que esses autores utilizam. A primeira delas relaciona-se com a produção poética literária que tem por objetivo uma valorização racial e simbólica da figura negra. Isto é, na representação autêntica dessas personagens, longe de evidenciar traços de silenciamento ou de subalternidade, elementos que a própria Conceição Evaristo apresenta nos conteúdos de seus textos. A segunda, e não menos importante, é no desenvolvimento da subjetividade negra dada à personagem e nas denúncias em relação às desigualdades sociais e raciais.

Sendo assim, a ideia da representação subjetiva do indivíduo negro como sujeito autêntico advém da valorização racial e da produção de imagens utópicas ${ }^{6}$ nos textos escritos por autores negros e negras e na constituição identitária desses indivíduos. Para Evaristo (2009):

Afirmando um contra-discurso à literatura produzida pela cultura hegemônica, os textos afro-brasileiros surgem pautados pela vivência de sujeitos negros/as na sociedade brasileira trazendo experiências diversificadas, desde o conteúdo até os modos de utilização da língua (EVARISTO, 2009, p. 27).

Conceição Evaristo faz parte deste grupo de autores negros que, no Brasil, difundem uma literatura que é propriamente negra. Em Becos da Memória, a narradora Maria-Nova recupera a memória de seus ancestrais, resgatando as histórias contadas por cada personagem da favela:

Maria-Nova, em um barraco desses há uma menina de sua idade. Quantos anos você tem? Treze. Isto mesmo, treze anos. A menina sonha. Infantis desejos, guardar na palma das mãos estrelas e lua. Armazenar chocolates e

\footnotetext{
${ }^{6}$ Resumidamente, esse termo está em referência às aspirações de transformações políticas, sociais e libertárias, produzidas por alguns textos literários. Benjamin Abdala Junior (2003) compreende a criação de imagens utópicas através do "sonho diurno" do escritor, ou seja, a partir de suas potências subjetivas, que nos textos literários manifestam-se na esperança de transformação utópica/ libertária.
} 
maçãs. Ter patins para dar passos largos... A mãe da menina sonha leite, pão, dinheiro. Sonha remédios para o filho doente, emprego para o marido revoltado e bêbado. Sonha um futuro menos pobre para a menina. A mãe da menina sonha ter nenhuma necessidade. Sonha dinheiro, dinheiro, dinheiro... (EVARISTO, 2017, p. 37).

A narradora traz à tona a memória coletiva de seu grupo social, em uma forma de reverter a posição desses sujeitos, que estão inseridos em uma ordem social racista, colonizada e patriarcal. A construção desse discurso tem o poder de evidenciar as diversas denúncias oriundas do contexto das favelas. Em uma linguagem simples, mas muito tocante, Conceição Evaristo abre as asas da liricidade em um romance que tem como principal pano de fundo as memórias de um grupo socialmente marginalizado.

Nessa perspectiva, a memória aparece como parte central do romance, abordada, inclusive, no próprio título, Becos da Memória, em uma possível referência aos becos que compõem a estrutura física da favela e ao emaranhado de lembranças que se acomodam na mente humana. Dessa forma, o romance apresenta as inúmeras histórias que povoaram o passado da autora, tais como as de Tio Totó, Bondade, Negro Alírio, Maria-Velha, Vó Rita, Cidinha-Cidoca, entre outras, as quais ficaram guardadas em becos de sua memória até o momento no qual, revivendo o próprio passado, a autora as trouxe de volta ao presente, por meio da composição da narrativa:

Sempre sabíamos quando Vó Rita estava chegando. Ela vinha cantarolando ou falando sozinha, às vezes, até sozinha sorria, gargalhava mesmo. E não era louca, Vó Rita! Vó Rita era boa, muito boa. Hoje, quando penso em Vó Rita, é como se pensasse no mistério e na plenitude da vida (EVARISTO, 2017, p. 69).

No entanto, o rio da memória não se apresenta como um discurso linear. Do mesmo modo, o discurso apresentado por Evaristo (2017) não segue uma ordem cronológica, ele se apresenta segundo o fluxo memorialístico, o qual avança e regride no tempo, expondo ora determinadas histórias, ora outras. Narrar a própria história, nesse sentido, é um exercício que exige grande esforço memorialístico por parte do narrador. Muitas vezes, é necessário recorrer à memória de terceiros ou, ainda, preencher as lacunas que o esquecimento provoca com narrativas imaginadas, detalhes construídos e inventados pelo presente, que garantem um sentimento de integridade ao passado rememorado. A narrativa de Becos da memória, conforme a própria autora admite no prefácio da obra, é uma reunião de ficção e relatos oriundos de um passado herdado de narrativas familiares, que ela incorporou às suas próprias lembranças. No intuito de construir um relato que retratasse sua infância na favela, ela dá voz 
à Maria-Nova, que reúne aquilo que se lembra de seu passado e das narrativas da vida de seu povo, para compor o romance.

"E como lidar com uma memória ora viva, ora esfacelada? Surgiu então o invento para cobrir os vazios de lembranças transfiguradas. Invento que atendia ao meu desejo de que as memórias aparecessem e parecessem inteiras" (EVARISTO, 2017, p. 11). De acordo com o questionamento feito por Conceição Evaristo (2017), a ficção é uma forma de lidar com o esquecimento que ameaça as memórias. O caráter ficcional das narrativas de memória permite a criação de fatos não vividos, mas que se ajustam à memória pessoal, preenchendo lacunas e acrescentando detalhes que colorem o passado, deixando-o mais vivo. Esses ajustes garantem à memória pessoal um todo mais coerente, estruturado de acordo com as relações sociais e com a afetividade daquele que se lembra. Becos da memória, sendo assim, apresenta-se como um relato de Evaristo sobre o próprio passado, colorido pela imaginação da escritora, que recorre a composição ficcional para criar um romance capaz de abrigar todos os personagens que habitaram sua infância.

O enredo composto pelo resgate dessas lembranças e a forma discursiva utilizada na representação dos acontecimentos e das personagens remetem ao conceito de escrevivência desenvolvido por Evaristo (2007), o qual possui uma forte ligação com a questão da memória dentro da literatura afro-feminina. Ele se refere à escrita marcada pela subjetividade de mulheres negras, para as quais esse processo reflete o corpo e as experiências de vida. Assim, a escrevivência se apresenta como conceito pelo qual pode-se interpretar a narrativa dessas autoras, tendo como princípio o narrar sobre si e a narração de experiências ficcionalizadas durante a criação literária. Nesse sentido, escrever torna-se um processo não apenas de invenção de histórias ou de recuperação das memórias vivenciadas, mas da expressão do que significa ser mulher e negra dentro de nossa sociedade e as formas como essas condições influenciam a vida e as experiências dessas mulheres enquanto escritoras.

Evaristo (2007) apresenta nas origens de sua escrita, a forma como a condição de vida e as narrativas passadas de seu povo constituíram as bases do que hoje ela apresenta como literatura:

E se inconscientemente desde pequena, nas redações escolares eu inventava outro mundo, pois dentro dos meus limites de compreensão, eu já havia entendido a precariedade da vida que nos era oferecida, aos poucos fui ganhando uma consciência. Consciência que compromete a minha escrita como um lugar de auto-afirmação de minhas particularidades, de minhas especificidades como sujeito-mulher-negra (EVARISTO, 2007, p. 20). 
A consciência de ter na escrita um lugar no qual pode narrar as próprias especificidades reforça a necessidade de utilizar o conceito de escrevivência para entender as narrativas dessas mulheres. Mais do que histórias, as obras dessas escritoras apresentam vivências que marcaram os corpos e as almas de seu povo. A escrita de Evaristo passa pela condição de mulher e negra frente à sociedade brasileira, condições que nossa sociedade insiste em inferiorizar, seja por meio da hipersexualição do corpo da mulher negra através de discursos construídos pela mídia e que reforçam estereótipos, ou da pouca representatividade midiática que até alguns anos não existia. A participação de mulheres negras e homens negros em novelas, minisséries, entre outros produtos midiáticos, restringia-se aos papéis subalternos e pouco relevantes para as narrativas. É muito recente o debate que repensou em questões representativas, como vemos hoje, que levantaram a importância do protagonismo negro nesses meios de comunicação.

E, para além disso, a própria autora assinala que: "A escre(vivência) das mulheres negras explicita as aventuras e as desventuras de quem conhece uma dupla condição, que a sociedade teima em querer inferiorizada, mulher e negra" (EVARISTO, 2005, p. 6). Dessa forma, sua escrita é fruto da sua vivência e da de milhares de mulheres, que são representadas na escrita do romance em questão e nas memórias de Maria-Nova:

\footnotetext{
Maria-nova olhou novamente a professora e a turma. Era uma história muito grande! Uma história viva e nascida das pessoas, do hoje, do agora. Era diferente de ler aquele texto. Assentou-se e, pela primeira vez, veio-lhe um pensamento: quem sabe escreveria esta história um dia? Quem sabe passaria para o papel o que estava escrito, cravado e gravado no seu corpo, na sua alma, na sua mente (EVARISTO, 2017, p.150-151).
}

A vontade de Maria-Nova de retratar as experiências que ficaram cravadas em si mesma demonstra como a escrita e a vivência estão interligadas. A impossibilidade de se desvencilhar da condição de sujeito-mulher-negra é um dos aspectos que conceitua a escrevivência, pela qual podemos perceber a escrita como forma de insubordinação à lógica eurocêntrica e hegemônica, fazendo com que as obras de autoras negras possam ser lidas como relatos de um discurso silenciado. A escrita emerge em um sentido denunciativo de estruturas sociais que se perpetuaram ao longo de nossa história, agregando à voz da narradora os milhares de vozes femininas que foram caladas ao longo dos tempos. Dessa maneira, as experiências vividas pela "sujeito-mulher-negra" (EVARISTO, 2007, p. 20) tornam-se matéria poética para a literatura, ecoando um discurso coletivo que fora por muito tempo silenciado, em função do colonialismo. 


\section{O SILÊNCIO COMO ESTRATÉGIA COLONIAL}

O silêncio surge, muitas vezes, como uma condição imposta aos grupos minoritários. No que tange à memória, o silenciamento dessas vozes aparece como estratégia das classes dominantes na busca pela homogeneização do passado nacional e da consequente conquista do poder. A memória dos povos colonizados foi, muitas vezes, silenciada pela voz do conquistador, que buscou em instâncias culturais, religiosas e linguísticas, além do extermínio dessas populações, apagar o passado desses povos, substituindo-os pela história da metrópole, principalmente nos períodos imperiais.

Nessa perspectiva, a literatura pós-colonial deve ser compreendida como a produção artística literária produzida por povos colonizados, entre o século XV e XX, por explicitar, justamente, relações de dominação entre colonizadores e colonizados. Thomas Bonicci (1998) observa que para a leitura de literaturas pós-coloniais, pode-se utilizar como abordagem teórica, a crítica pós-colonialista, a qual se dá como uma alternativa para compreender os processos imperiais e suas influências, de forma que "Essa abordagem envolve: um constante questionamento sobre as relações entre a cultura e o imperialismo para a compreensão da política e da cultura na era da descolonização" (BONICCI, 1998, p. 20).

Bonicci (1998) encara que o silêncio e a opressão são elementos que estão presentes nas sociedades pós-coloniais. Em Becos da Memória, esses elementos podem ser observados na interação entre as diferentes classes sociais e atravessam a maior parte da história dos personagens ali representados. O silêncio atinge a vida de personagens como Cidinha-Cidoca, a quem o fulgor da vida desaparece em face do "desfavelamento"7 que ameaça a vida daquelas famílias:

Cidinha Cidoca andava muito quieta ultimamente. Quem te viu quem te vê!... Alheia pelos cantos do botequim, nem cachaça exigia mais. Suja, descabelada, olhar parado no vazio. Se lhe dessem um trago, bebia. Se não lhe dessem, nem da secura na boca reclamava mais (EVARISTO, 2017, p. 21).

É nesse panorama, que a narrativa organizada por Evaristo (2017) vai tecendo diversas relações com elementos que estão muito presentes em nossa sociedade. A autora convoca, em seu texto literário, diversas personagens que colhem a herança deixada pelo colonialismo. Por

\footnotetext{
${ }^{7}$ Um dos fatos narrados pela memória de Maria-Nova, nesta narrativa, é o processo de desfavelamento que ameaça a vida de todas as personagens que habitam a favela. Elas perdem suas casas e separam-se de seus amigos e familiares.
} 
isso, essa escrita torna-se totalmente marcada na perspectiva de dar voz a esses sujeitos. Desse modo, a autora propõe diversas problematizações e reflexões acerca de uma situação histórica e convoca a necessidade de conceber a escrita, ou seja, a organização desta narrativa, para romper com estruturas que estão, ainda, muito visíveis em nossa sociedade.

Homi Bhabha (1984) observa as relações entre a narrativa e o sujeito colonizado. O autor defende que é através da narrativa que aquele pode reverter a sua posição subalterna nas sociedades pós-coloniais. Veremos, então, que o silêncio é um elemento que perpassa a história da pós-colonialidade, sob algumas perspectivas. Pois, para Bhabha (1984) esses corpos sociais necessitam da narrativa para subverter a hegemonia, e vencer o silêncio do sujeito subjugado. Dessa maneira, a narrativa de Evaristo (2017) é um ato de descolonização frente ao silêncio imposto às memórias e às narrativas desses sujeitos. Ela rompe com as barreiras que a sociedade lhe impõe e utiliza a escrita como ferramenta para lutar contra o silenciamento imposto ao seu povo:

Um dia, agora ela já sabia qual seria a sua ferramenta, a escrita. um dia, ela haveria de narrar, de fazer soar, de soltar as vozes, os murmúrios, os silêncios, o grito abafado que existia, que era de cada um e de todos. MariaNova um dia escreveria a fala de seu povo (EVARISTO, 2017, p. 133).

A luta travada pela memória das minorias contra a opressão de um discurso histórico institucionalizado é um dos pontos que Maria-Nova resgata em suas memórias. Para ela a luta contra a escravidão não acabara, as vozes de um passado de sofrimentos condenado ao silêncio de uma sociedade opressora ecoam em sua mente e o paralelo "senzala-favela" permanece cravado no corpo e na memória da menina. A escrevivência surge como possibilidade de retratar o próprio passado no romance, aplicar as experiências pessoais na construção das personagens e do todo que compõe a narrativa, tornando-a peça significante no entendimento do que é a literatura produzida por mulheres negras.

\section{DENÚNCIAS DA ESCREVIVÊNCIA: EXPONDO MARCAS DE VIOLÊNCIA}

Como assinala o presente artigo, a compreensão do funcionamento do conceito de escrevivência, em narrativas negras-femininas, é muito importante, pois pode apresentar uma nova forma de leitura, recepção e crítica das literaturas produzidas por escritoras negras. A escrita das vivências dessas mulheres cria uma literatura amplamente marcada por memórias permeadas de sentimento, revoltas e lutas para a conquista de uma posição digna perante a 
sociedade. Nessa perspectiva, podemos, novamente, retornar à escritora negra-brasileira, que talvez tenha sido a precursora desse movimento expositório de experiência histórica enquanto mulher, negra e pobre em uma sociedade racista e patriarcal, como o Brasil.

Carolina Maria de Jesus expôs em Quarto de Despejo, sua obra principal, um retrato do Brasil, denunciando as violências enfrentadas em sua vivência, em seu cotidiano: "Vou escrever um livro referente a favela. Hei de citar tudo que aqui se passa. E tudo que vocês me fazem. Eu quero escrever o livro, e vocês com estas cenas desagradáveis me fornece (sic) os argumentos" (JESUS, 1993, p. 17). Nessa perspectiva, a escritora revela as mazelas sociais como a fome, o racismo, a falta de dinheiro e de oportunidade que faziam parte de sua existência, colocando em voga a sua própria perspectiva de olhar o mundo, denunciando as respectivas violências sofridas.

É necessário notar que as identidades de mulheres negras como Carolina, Conceição e tantas outras se dão, também, no contato constante com a violência, justamente pela questão da tripla inferiorização que sofrem as mulheres negras - gênero, raça e classe. Pensar nisso, faze-nos refletir sobre o percurso histórico realizado por essas mulheres, no Brasil e na América Latina. Percurso esse que remonta ao caminho diaspórico entre África e América, o qual resultou em diversos tipos de violência e exploração. Dulce Pereira (1988) afirma que:

Foi provavelmente em 1549 que Tome de Souza trouxe os primeiros africanos para o Brasil. Desde então, a mulher negra, nesta parte do mundo, tem sido ao mesmo tempo vítima de toda forma de violentação, enquanto povo e enquanto indivíduo. No entanto, ela tem sido também uma das principais personagens ativas na história do País. Ironicamente, é o principal agente, ao lado dos senhores brancos, da definição da personalidade cultural desta nação. (PEREIRA, 1988, p. 3).

Para Du Plessis (1985, p. 46) "Uma mulher da colônia é uma metáfora da mulher como colônia", uma vez que em nossa sociedade instaurou-se uma violência de gênero contra as mulheres, promovida pelo olhar e por valores machistas e patriarcais. Assim a própria Evaristo (2005) afirma que a mulher negra é duplamente colonizada, pois enfrenta as dificuldades provenientes da inferiorização do gênero, bem como, da raça.

No romance Becos da Memória, Maria-Nova relata as dificuldades que as mulheres que partilham com ela essa condição de tripla inferiorização passam em busca da sobrevivência. Ditinha mora com seu pai paralítico, os três filhos e a irmã que aparece raramente em casa, um barraco de dois cômodos na favela. A condição de vida precária desanima a mulher, que se sente ainda mais inferiorizada ao contrastar sua situação com a de 
Dona Laura, proprietária do apartamento em que Ditinha trabalha como doméstica. A violência aparece de maneira subjetiva, através do sentimento de inferioridade que a personagem sente em relação a patroa. Esse sentimento atravessa a identidade de Ditinha que, por sua condição social enquanto mulher negra, favelada e doméstica ao se olhar no espelho não reconhece sua própria beleza.

Ditinha olhou para a patroa e sentiu o ar de aprovação no rosto dela. Como D. Laura era bonita! Muito alta, loira, com os olhos da cor daquela pedra das joias. Ditinha gostava muito de D. Laura e D. Laura gostava muito do trabalho de Ditinha. Olhando e admirando a beleza de Dona Laura, Ditinha se sentiu mais feia ainda. Baixou os olhos envergonhada de si mesma (EVARISTO, 2017, p. 100-101).

Nesse trecho, Ditinha julga a si mesma e à patroa por meio dos padrões de beleza que valorizam características europeias, como pele clara e cabelos loiros em detrimento de sua própria beleza, enquanto mulher negra de cabelo crespo. A diferença de classe social entre ambas é outro fator que faz Ditinha sentir-se ainda mais inferiorizada em relação à patroa. Ela não consegue enxergar sua vida fora dos padrões sociais impostos pela sociedade, "E se eu tivesse vestidos e sapatos e soubesse arrumar os meus cabelos? (Ditinha detestava o cabelo dela.) Mesmo assim eu não assentaria com essas joias" (EVARISTO, 2017, p. 99). Enquanto D. Laura detém o acesso a bens materiais e a uma posição social que lhe garante privilégios pelo fato de ser branca e de pertencer a uma classe média/alta; Ditinha se vê presa ao trabalho doméstico e, dessa forma, experiencia as diferenças sociais impostas, desde o período colonial, por nossa sociedade.

A distância social entre Ditinha e sua patroa faz com que a personagem sinta um certo fascínio por aquele mundo tão distante, um mundo que fora negado à sua existência e "aos seus", de forma que a personagem realize as tarefas domésticas com eficiência profunda e com esforço genuíno. Mesmo em sua posição subalternizada, o trabalho soa como um alívio ao lembrar-se de sua condição e sua "esperteza" ao realizar as tarefas a si designadas, chega a soar como um consolo, pois ela não vê alternativa a não ser esta que lhe foi imposta.

O romance de Evaristo (2017) é permeado de cenas como essa, que representam as dificuldades que as mulheres enfrentam em seu cotidiano, simplesmente, pelo fato de serem mulheres e negras, "Neste livro de corte tanto biográfico quanto memorialístico, nota-se o que a autora chama de escrevivência, ou seja, a escrita de um corpo, de uma condição, de uma experiência negra no Brasil" (OLIVEIRA, 2009, p. 622). A inferiorização que Ditinha sente ao se comparar à patroa é fruto da construção de um padrão de beleza imposto. $\mathrm{O}$ conceito de 
escrevivência permite-nos depreender o sofrimento dessas personagens, visto que exibe "[...] a dimensão subjetiva do existir negro, arquivado na pele e na luta constante por afirmação e reversão de estereótipos" (OLIVEIRA, 2009, p. 622).

As violências retratadas por Evaristo (2017), no romance, podem ser entendidas como fruto das suas próprias vivências e daquelas que sua memória guardou do passado compartilhado em histórias que ouvia quando criança. Por esse motivo, a narração dessas memórias aparece com tanta força em sua vida. A necessidade de contar, de retratar aos demais o passado de seu povo como um ato de resistência ao esquecimento e ao silêncio que por muito tempo foram-lhes impostos pelo sistema colonial.

\section{(RE)ESCREVENDO EXISTÊNCIAS COMO ATOS DE DESCOLONIZAÇÃO}

Evaristo (2009), em suas reflexões enquanto pesquisadora da literatura afro-brasileira, reflete sobre alguns elementos que perpassam a existência de um corpus literário negro no Brasil, o qual seria “[...] uma produção escrita marcada por uma subjetividade construída, experimentada, vivenciada a partir da condição de homens negros e de mulheres negras na sociedade brasileira" (EVARISTO, 2009, p. 17). Segundo ela há, logicamente, uma diferenciação na representação das personagens negras em textos cunhados por escritores negros e não-negros. Nos textos em que a escrita perpassa por essa subjetividade condicional, no que tange o contato e a vivência com o racismo, é possível perceber que:

Personagens são descritos sem a intenção de esconder uma identidade negra e, muitas vezes, são apresentados a partir de uma valorização da pele, dos traços físicos, das heranças culturais oriundas dos povos africanos e da inserção/exclusão que os afrodescendentes sofrem na sociedade brasileira. Esses processos de construção de personagens e enredos destoam dos modos estereotipados ou da invisibilidade com que negros e mestiços são tratados pela literatura brasileira, em geral (EVARISTO, 2009, p. 19-20).

Em Becos da Memória, essa perspectiva de valorização cultural e étnica da figura negra e, também, da memória que envolve a cultura afro-brasileira pode ser claramente observada. E, nesse sentido, Janmohammed (1988) verifica que uma das estratégias que autores de literaturas pós-coloniais utilizam é, justamente, a contraposição das figuras colonizador e colonizado, em uma perspectiva que produza traços e elementos "autênticos" da figura do colonizado, contraposta a construção de uma figura negativa do colonizador. No romance, vemos a exaltação das narrativas negras como um ato de valorização do sujeito, 
uma dessas narrativa é a história de vida de Negro Alírio, a qual Dora admira.

Dora também gostou da história de Negro Alírio. Nem o espanhol, que era um homem bastante viajado, tinha uma vida bonita assim. Imagine só, um homem tão pobre quanto ela, tão simples, e que sabia ler. Conhecia poucas pessoas negras que soubessem ler. Achou mais interessante ainda porque, só depois de muito conversarem, foi que se lembraram de falar os nomes. Ela disse se chamar Dora. Ela gostava muito do nome dela, aliás Dora gostava muito de si própria. Ele disse se chamar Negro Alírio. Negro deveria ser apelido e Alírio o nome, mas ele dissera Negro Alírio. Gostou de ouvir a palavra negro pronunciada por um negro, pois o termo negro, ela só ouvia na voz de branco, e só para xingar: negro safado; negro filho da puta, negro baderneiro e tantos defeitos mais! (EVARISTO, 2017, p. 94-95).

Os personagens que povoam a narrativa de Evaristo (2017), são representados de maneira autêntica. Trata-se de personagens que possuem em suas resistências diárias o enfrentamento ao poder hegemônico, bem como a luta por novas condições sociais. $\mathrm{O}$ discurso sustentado por autores negros desconstrói o imaginário dos grupos dominantes, o qual se manifestou na literatura brasileira e perpetuou a ideia de animalidade e subalternidade na representação de personagens negros.

Frantz Fanon (1990) compreende o processo de descolonização de forma violenta, na maneira que o colonizado sai de sua posição subalterna, imposta socialmente, e transforma isso na luta contra o colonizador e o sistema opressivo. Nesse panorama, entendendo esse processo dentro da mesma perspectiva de Fanon (1990), observamos que o romance Becos da Memória expõe as mazelas sociais oriundas do contexto das senzalas e das favelas, atuando como instrumento pelo qual Evaristo (2017) tenta subverter a realidade. Nesse sentido, ao recuperar essas histórias e organizá-las através de uma narrativa, a personagem-narradora Maria-Nova traz à tona esse processo, saindo de sua posição de subalternidade, enquanto mulher negra e favelada, para denunciar as diversas violências e opressões promovidas por nossa sociedade.

No romance Becos da Memória, a escrita atua, ao mesmo tempo, como meio pelo qual se denuncia as violências impostas por uma sociedade de hegemonia branca e como homenagem aos que passaram pela infância de Maria-Nova, uma tentativa de não deixar que esses personagens sejam apagados da própria memória e garantir que vivam, também, na memória daqueles que venham a ler a narrativa:

Escrevo como uma homenagem póstuma à Vó Rita, que dormia embolada com ela, a ela que nunca consegui ver plenamente, aos bêbados, às putas, aos malandros, às crianças vadias que habitam os becos de minha memória. 
Homenagem póstuma às lavadeiras que madrugavam os varais com roupas ao sol. Âs pernas cansadas, suadas, negras, aloiradas de poeira do campo aberto onde aconteciam os festivais de bola da favela. Homenagem póstuma ao Bondade, ao Tião Puxa-Faca, à velha Isolina, à D. Anália, ao Tio Totó, ao Pedro Cândido, ao Sô Noronha, à D. Maria, mãe do Aníbal, ao Catarino, à Velha Lia, à Terezinha da Oscarlinda, à Mariinha, à Donana do Padin. Homens, mulheres, crianças que se amontoaram dentro de mim, como amontoados eram os barracos de minha favela. (EVARISTO, 2017, p. 16).

Escrever a própria história, ou contar a dos demais, surge como um ato de resistência ao esquecimento que espreita as memórias. Ao decidir fixar por escrito as histórias que lembra de seu passado, a narradora cria um suporte material para suas lembranças, permitindo que essas persistam no tempo, sobrevivendo aos processos que assolam as recordações. Isso se dá devido ao fato de a escrita funcionar como um estabilizador da memória “[...] o único meio de salvar tais lembranças, é fixá-las por escrito em uma narrativa seguida uma vez que as palavras e os pensamentos morrem, mas os escritos permanecem" (HALWACHS, 1990, p. 81).

A escrita também pode ser vista como uma forma de dar voz aos moradores da favela e da memória de Maria-Nova, trazendo à tona histórias que há muito são excluídas pelos discursos oficiais. Segundo Pollak (1989), a memória nacional é a forma mais acabada de memória coletiva e por esse motivo é constante foco de disputa entre os grupos que desejam assumir o poder. Assim, a necessidade de dar voz às narrativas marginais é expressa pelo fato de elas atuarem como a manutenção das memórias dos grupos minoritários, as quais são muitas vezes relegadas ao esquecimento em favor de uma memória nacional que seleciona a versão do passado que deseja incorporar como sendo o passado do país. Geralmente, o ponto de vista por ela apresentado é o do grupo dominante e, por esse motivo, as memórias consideradas de menor prestígio, por pertencerem aos povos colonizados, são condenadas ao silenciamento.

Sendo assim, as memórias que Maria-Nova reúne no romance são versões que permanecem excluídas da memória oficial do país, sobrevivendo em discursos que circulam em meios familiares. As histórias narradas por sua família e por Bondade e os acontecimentos que acometem os outros moradores da favela revelam as faces de uma sociedade que a história oficial procura omitir.

\section{CONSIDERAÇÕES FINAIS}

Conceição Evaristo faz parte de um grupo de escritoras negras que contribuíram para a 
reflexão das subjetividades, preconceitos e sobretudo para a consolidação de uma representação identitária de mulheres negras, em nossa literatura. Essa representação pode ser pensada sobre duas maneiras: a primeira delas seria enquanto escritora e crítica literária, um aspecto da vida de Conceição, portanto, mais individual; a segunda pode ser pensada em um parâmetro de cunho coletivo, já que a autora utiliza a sua escrita para demonstrar as vivências, os sonhos, as frustações e as dificuldades que a população negra, em geral, enfrenta em nosso país. Por este motivo, buscamos destacar neste artigo a importância de textos literários que problematizam as diversas violências sociais enfrentadas pela população negra, como faz o romance Becos da Memória.

A escrita surgiu como um meio de combate às violências e como um ato de descolonização, pois questiona a história oficial dando vez às vozes marginalizadas de nossa sociedade. A autora, Conceição Evaristo, utiliza da construção de discursos liricizados na sua narrativa, para retratar os diversos sofrimentos vivenciados pelo povo negro, subvertendo a lógica de representação e composição para esses personagens. Em Becos da Memória, concluímos, então, que as subjetividades negras, que povoam esta narrativa, ganham corpo, voz, autenticidade e memória, de um modo amplo e coletivo.

Portanto, o texto literário negro, situa-se em um sistema de narrativas que subvertem a lógica eurocêntrica, pela maneira que passam a ressignificar visões promulgadas pelo centro hegemônico, e dessa maneira difundem um discurso que convoca e representa as diversidades étnicas, sexuais e de gênero. Essa literatura revela a vivência dos povos negros expressos dentro de sua própria perspectiva. Por isso, quando pensamos em uma mulher negra que está publicando, escrevendo, divulgando a sua intelectualidade veremos a postura de um enfrentamento que ultrapassa as estruturas sociais impostas por nossa sociedade.

Por este motivo, o conceito de escrevivência torna-se extremamente importante na leitura de narrativas negras-femininas. Ele permite aproximar os textos literários das realidades nas quais eles são compostos, isto é, como forma de compreensão às subjetividades das mulheres-negras e as violências por elas sofridas diariamente, e pelo modo de potencializar narrativas que entrelaçam em seu corpo experiência e ficção, memória e história. Sendo assim, esse conceito foi crucial para o entendimento do romance Becos da Memória como uma obra que retrata para além de uma narrativa de memória, uma expressão da subjetividade de um passado marcado pelo sofrimento de alguém que conheceu na pele o preconceito da sociedade e encontrou na escrita um meio de resistir e lutar contra isso. Dessa maneira, finalizamos o presente artigo com uma famosa citação da escritora Conceição Evaristo afirmando que "A nossa escrevivência não pode ser lida como histórias para "ninar 
os da casa grande" e sim para incomodá-los em seus sonos injustos" (EVARISTO, 2007, p. 21).

REFERÊNCIAS

ABDALA JUNIOR, B. De Vôos e Ilhas: Literatura e Comunitarismos. Cotia: Ateliê Editorial, 2003.

ANTONIO, Carlindo Fausto. Cadernos Negros: esboço de análise. Tese (Doutorado em Teoria Literária) - Universidade Estadual de Campinas. São Paulo, 2005.

BALANDIER, George. Préface. In: SMOUTS, Marie-Claude (dir.). La situation postcoloniale. Paris, Presses de Sciences Po, 2007, p. 24.

BHABHA, H. Of Mimicry and Men: The Ambivalence of Colonial Discourse. October, v. 28, n. 1, p. 125-133, 1984.

The Other Question: Difference, Discrimination and the Discourse of Colonialism. Screen, v. 24, n. 6, p. 18-36, 1983.

The right to narrate. Harvard Design Magazine, Cambridge, Summer. On-line. Disponível em: Disponível em: https://goo.gl/3JnEHX. Acesso em: 10 de mar. de 2020.

BONNICI, T. Introdução ao estudo das literaturas pós-coloniais. Mimesis, Bauru, v. 19, n. 1, p. 07-23, 1998.

Aspectos da Teoria Pós-Colonial. In BONNICI, T. Pós-colonialismo e literatura: estratégias de leitura. 2. ed. revista e ampliada. Maringá: Eduem, 2012.

BROOKSHAW, David. Raça e cor na literatura brasileira. Porto Alegre, Mercado Aberto, 1983.

Cadernos Negros, n $^{\circ}$ 1. São Paulo: Edição dos Autores, 1978.

Du PLESSIS, R. B. Writing beyond the Ending: Narrative Strategies of 20th Century Women Writers. Bloomington: Indiana UP, 1985.

DUARTE, Eduardo de Assis. Literatura, política, identidades. Belo Horizonte: FALEUFMG, 2005. $138,2010$.

Por um conceito de literatura afro-brasileira. Terceira Margem, v. 14, n. 23, p. 113-

EVARISTO, Conceição. Becos da memória. Rio de Janeiro: Pallas, 2017.

Da grafia-desenho de minha mãe, um dos lugares de nascimento de minha escrita. In: ALEXANDRE, Marcos Antônio (org). Representações performáticas brasileiras: teorias, práticas e suas interfaces. Belo Horizonte: Mazza Edições, 2007. 
Gênero e etnia: uma escre(vivência) de dupla face. In: MOREIRA, Nadilza Martins de Barros; SCHNEIDER, Liane (Org.). Mulheres no mundo: etnia, marginalidade e diáspora. João Pessoa: Ideia; Editora Universitária UFPB, 2005. $\overline{31,2009}$.

Literatura Negra: uma poética de nossa afro-brasilidade. Scripta, v. 13, n. 25, p. 17-

PEREIRA, Dulce. Mulher Negra: Ditando as Regras da História.Cunhary, v.1, n. 0, p. 3-7, 1988.

PROENCA FILHO, Domício. A trajetória do negro na literatura brasileira. Estudos avançados., São Paulo, v. 18, n. 50, p. 161-193, Abril. 2004 . Disponível em: https://www.scielo.br/scielo.php?script=sci_arttext\&pid=S0103-40142004000100017. Acesso em: 08 de jun de 2020.

HALBWACHS, Maurice. A Memória Coletiva. Trad. Lautrent Léon Schaffter. São Paulo: Vértice. 1990.

FANON, F. The Wretched of the Earth. Harmondsworth: Penguin, 1990.

JESUS, Carolina Maria de. Quarto de despejo: diário de uma favelada. São Paulo: Ática, 1993.

JANMOHAMMED, A. The Economy of Manichean Allegory: The Function of Racial Difference in Colonial Literature. Critical Inquiry, v. 12, n. 1, p. 59-87, 1988.

LOBO, Luiza. Crítica sem juízo. 2 ed. revista. Rio de Janeiro: Garamond, 2007.

OLIVEIRA, Luiz Henrique Silva de. "Escrevivência" em Becos da memória, de Conceição Evaristo. Estudos Feministas, Florianópolis, v. 17, n. 2, p. 621-623, 2009.

POLLAK, Michael. Memória e Identidade Social. Estudos Históricos, Rio de Janeiro, vol. 5. n. 10,1992 , p. $200-212$.

Memória, Esquecimento, Silêncio. Estudos Históricos, Rio de Janeiro, vol. 2. n. 3, 1989, p. 3-15.

SPIVAK, Gayatri Chakravorty. Pode o subalterno falar? Belo Horizonte: Editora da UFMG, 2010.

YATES, Frances. A arte da memória. Trad. Flavia Bancher. Campinas - SP. Editora Unicamp, 2007. 